\title{
$\underline{\text { Issues in Subject Analysis and Description of Political Cartoons }}$
}

\author{
Chris Landbeck \\ College of Information \\ Florida State University
}

TAGS: political cartoons, image indexing, subject analysis, aboutness, metadata

Political cartoons have historically been organized for very narrow and specific purposes when they have been organized at all. Collections to date have been of the works of a particular artist/writer, or have been collected to illustrate a particular historical event, mostly from times long past. The advent of the Electronic Age has given rise to far more expansive collections, sometimes bringing together in one source several authors who write on a large number of subjects across local, national, and international lines. However, the relative explosion in the number of political cartoon archives in electronic form has not brought about a corresponding rise in systems of organization for the cartoons. The development of a metadata system for political cartoons and other images of meaning would be a benefit for several communities, including political science, history, communications, art history, and those researchers in any field who are working with other specific subsets of images.

This paper begins with the assumption that we can divide the cataloging needs of political cartoons into three groups: bibliographic, descriptive, and subject. The bibliographic needs are fairly straightforward, as they have a number of similarities with other documents: authors or artist or some notation of the creator of the piece, date of publication (possibly the most crucial piece of information that can be included in the record), media used, and the like. Of greater 
importance is solving some of the problems inherent in describing the cartoon as we do other images, and in finding a way to describe its subject (or, as the case may be, subjects). These two items are the main searching points for cartoons in most cases, depending on whether the user has the cartoon before him, in which case the text of the cartoon is the first thing sought followed by visual entities, or if the user is seeking cartoons on a particular topic, which would generally lead to searching by subject. The problem with both of these is one of context. Where standard textual documents can carry context with them - where they can explain themselves - political cartoons, like all visual media, assumes that context will be plain to the user through means other than the image itself. Where a news story can carry explicit references that make the content of the article clear within a given context, a cartoon can only hope that the viewer has the requisite knowledge to "get it", and without this necessary common set of reference points, the meaning of the cartoon is lost.

Another assumption in this paper is that some sort of metadata schema would be the best method for describing political cartoons, because this will allow for a larger potential indexing pool than would larger and more formal cataloging systems and because it will allow the cartoon to be indexed faster, something that has been represented as a necessity for these short shelf-life items. The Visual Resources Association's Core 4.0 is used as an example in this paper; Dublin Core or the Library of Congress' MODS could also be used, but the intent of the VRA Core is to describe artwork, and serves as the best current metadata schema for the description of political cartoons. These three schema, among others, have similar problems in the description of cartoons and in providing the cartoon's subject. 


\section{Literature Review}

\section{Cartoons in General}

Academic literature directly commenting on indexing political cartoons is scarce; while there have been occasional flurries of articles on the subject of such images in general, and the even more occasional book on the subject, indexing political cartoons has not been the focus of intense scrutiny in library and information science. Chappel-Sokol (1996) documents and laments the lack of organization in political cartoon archives, noting that such collections are sometimes kept in shoeboxes and that the New Yorker had kept for years a highly informal indexing system consisting of whatever keywords a person might care to use to describe the image. Weitenkampf (1946) found that political cartoons are in fact historical documents, ones quite close to the feeling of the time on a given issue; he notes that even obvious partisanship in a cartoon is a commentary on the times and, as such, is a perhaps unintentional part of the historical record as well. Landbeck (2002) found that research subjects would universally use the words in a cartoon's caption, signs, or dialogue (when present) to search a database. Additionally he found that while subjects might group together certain cartoons on a regular basis, they would do so for different reasons. DeSousa and Medhurst (1982) describe cartoons as an inside joke between the cartoonist and the reader, where the image demands a great deal of political and current event awareness on the part of the reader as well as a good foundation in the allegorical references sometimes found in such cartoons. And Brinkman (1968) found that the effectiveness of political cartoons was enhanced by the presence of a like-minded editorial, and that written editorials are more effective in changing opinion than are editorial cartoons. 


\section{Cartoon Interpretation}

While articles about political cartoons in general usually deal with the history of such works, one specific subset of "articles about political cartoons" is those that deal with how cartoons are interpreted, what skills are needed and how often this task is done correctly. Bedient and Moore (1985) found that middle and high school students not only failed to interpret the subject and point of a cartoon correctly, but often had trouble identifying the actors in such works. This sentiment was echoed by Carl (1968), who studied adult interpretations of cartoons, finding that the point the artist intended to make was most often completely different than what people found in the work. Hunter, Moore, and Sewell (1991) found that proper interpretation of political cartoons required some grounding in the subject material, and a high degree of field independence - the ability to interpret the several parts of such images then correctly determine their relation to one another. In all cases, users had trouble properly identifying the subject of the cartoons, giving us pause to wonder if recording the subject can be done at all.

\section{Image indexing}

Roberts (2001) laments the missed opportunity presented by advances in technology to provide a comprehensive and usable way to search for images by subject of theme. The problem, she says, is that while the more "bibliographic" information has become more or less standardized, the more descriptive areas by which images might be accessed are largely neglected. Several authors have put forth different concepts as part of the solution. Svenonious (1994) suggests that some images are more documentary than others, and it is these that can benefit from subject- or context-indexing, something to be considered when indexing political cartoons. Shatford (1994) advocates considering when images are indexed (whether acquired or after inclusion in the collection), what groupings are based on within the collection, and trying to 
predict what groupings will be useful to the anticipated audience. Enser (2000) states that while CBIR is certainly an important place to start when describing images, concept-based image retrieval is more likely to fulfill the average user's needs better than the technical information that had previously held primacy. And Jörgensen (2003a) avers that there are five main considerations when indexing images in today's world: the collection as a unit, the anticipated user base, the vocabulary to be used, indexing needs, and the context of the image within the collection.

\section{Aboutness}

Twinned with subject indexing as a field of academic work is aboutness; where subject indexing is concerned with recording what a document is about, aboutness is concerned with determining what it is about. Mai (2004) suggests that the word and the idea are one and the same, and carries this idea into the realm of domain analysis; he claims that to build any sort of indexing scheme for a particular community one may study how questions are asked in that realm. This sentiment is echoed in his later work (2005) where a distinction is made between a document-centered approach and a domain-centered approach. Maron (1977) proposed that there are three different points of view that determine the ultimate aboutness of a document: the subjective about, determined by individual needs at the time of retrieval; objective about, which is more concrete and supported by the document itself; and retrieval about, which refers to the likelihood of the document being about something for a group of like-minded retrievers. Hjørland (2001) states that the aboutness of the subject shares most of its theoretical underpinnings with the ideas of subject, topic, field, discipline, and such, and that these ideas are separated by the needs of the indexer and the situation that a document is indexed in. Swanson (1986) holds that while the efficacy of a retrieval system is defined by the users of it and that this 
is a subjective measure, the design and testing of that same system is necessarily objective, an argument that can be carried over into the determination of aboutness as an ancillary argument supporting Mai.

\section{Visual Materials}

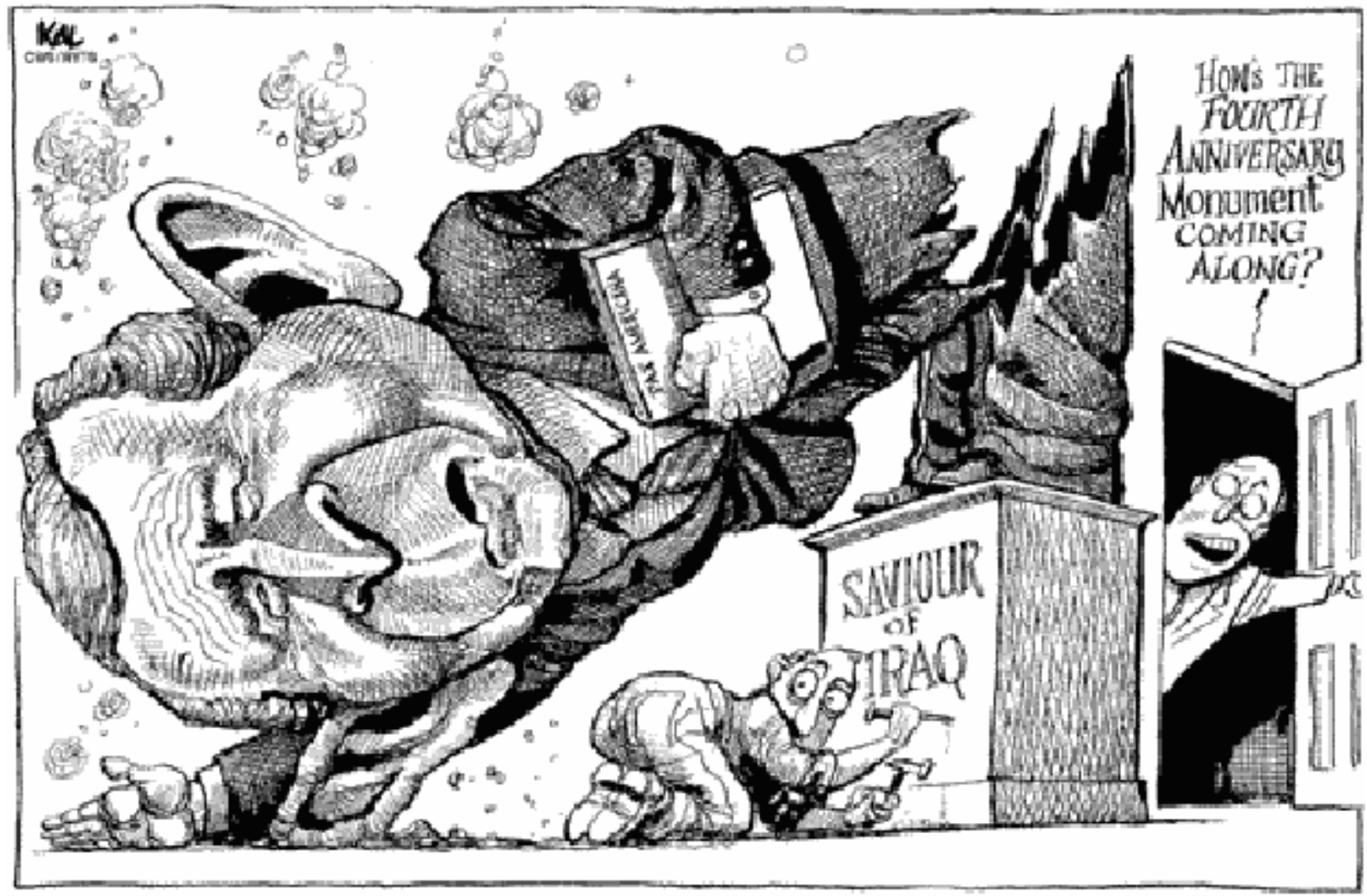

This cartoon (Kallaugher, 2007) carries with it sufficient reference points that context can be established well after the events that it refers to is in the news, given that the user can interpret the caricature properly as the junior President Bush. Using this, the mention of Iraq, and the reference to a fourth anniversary, one can infer that the cartoon comments on the legacy of President Bush vis-à-vis Iraq. That the image carries with it enough context to establish meaning is an unusual state of affairs. And a useful description of this cartoon would not be difficult to write, either; the identification of President Bush would certainly be in order, along with the 
statue, the two "anyman" characters, and all of the text either written or spoken. Either the description or the cartoon itself could be used to establish a link to the historical event that it comments on.

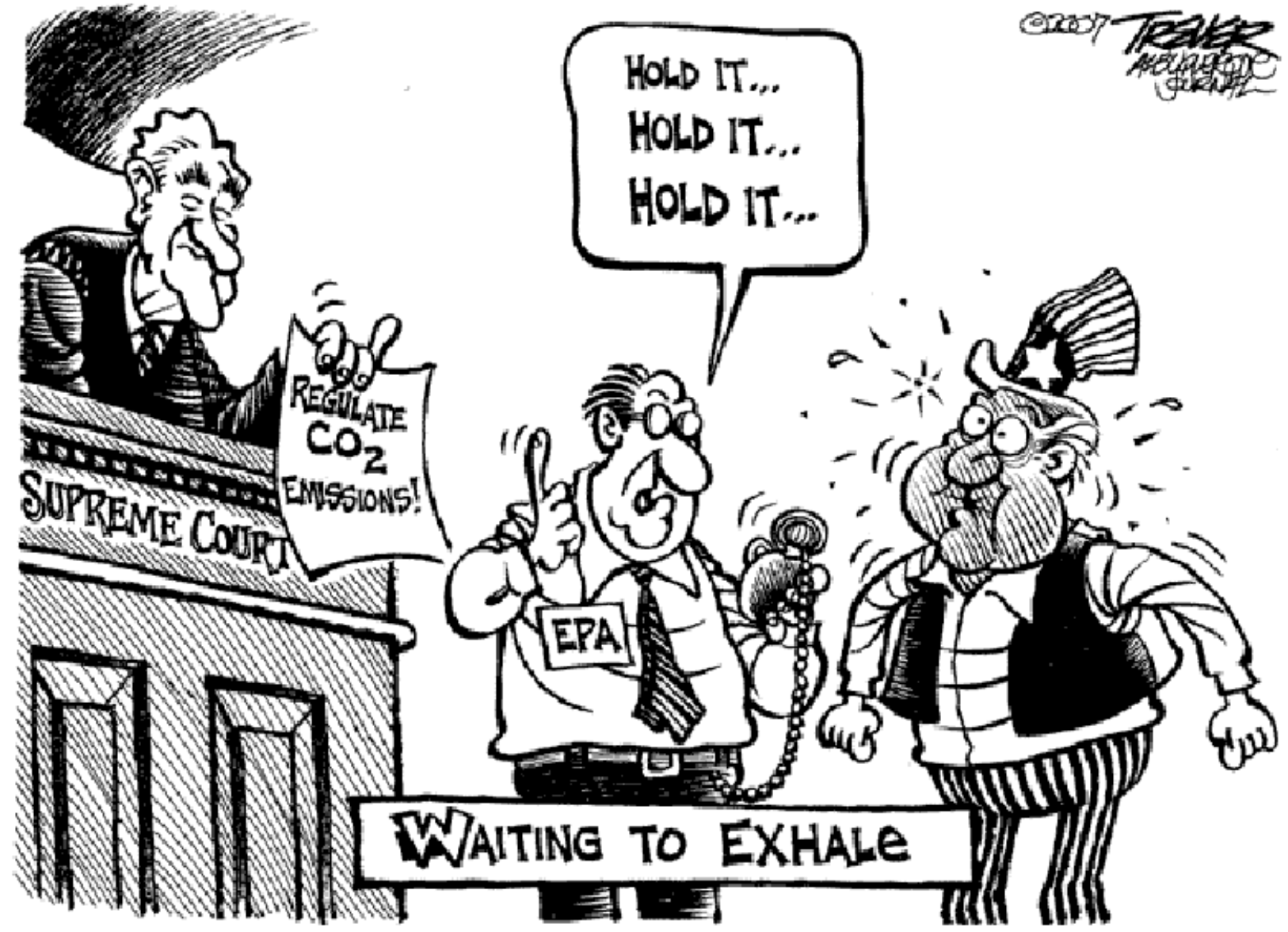

In this example (Trever, 2007), there is sufficient text to establish that this cartoon is a commentary of a Supreme Court decision regarding carbon dioxide emissions. Additionally, in the upper right-hand corner, we see a date, 2007. Together, this provides enough information that, if the event this cartoon speaks to is not already known, it can be researched. Absent any of the three key pieces - “Supreme Court”, “Regulate CO2 emissions”, or “2007” - the specific subject of this cartoon could not easily be discerned. In general terms, its meaning could be found, but it could not be linked to a particular event. But a description here would be less useful 
than the one of the previous cartoon because, while it is easy to describe the Justice holding a piece of paper with the words "Regulate CO2 emissions" on it, it is difficult to convey the meaning of this visual gesture.

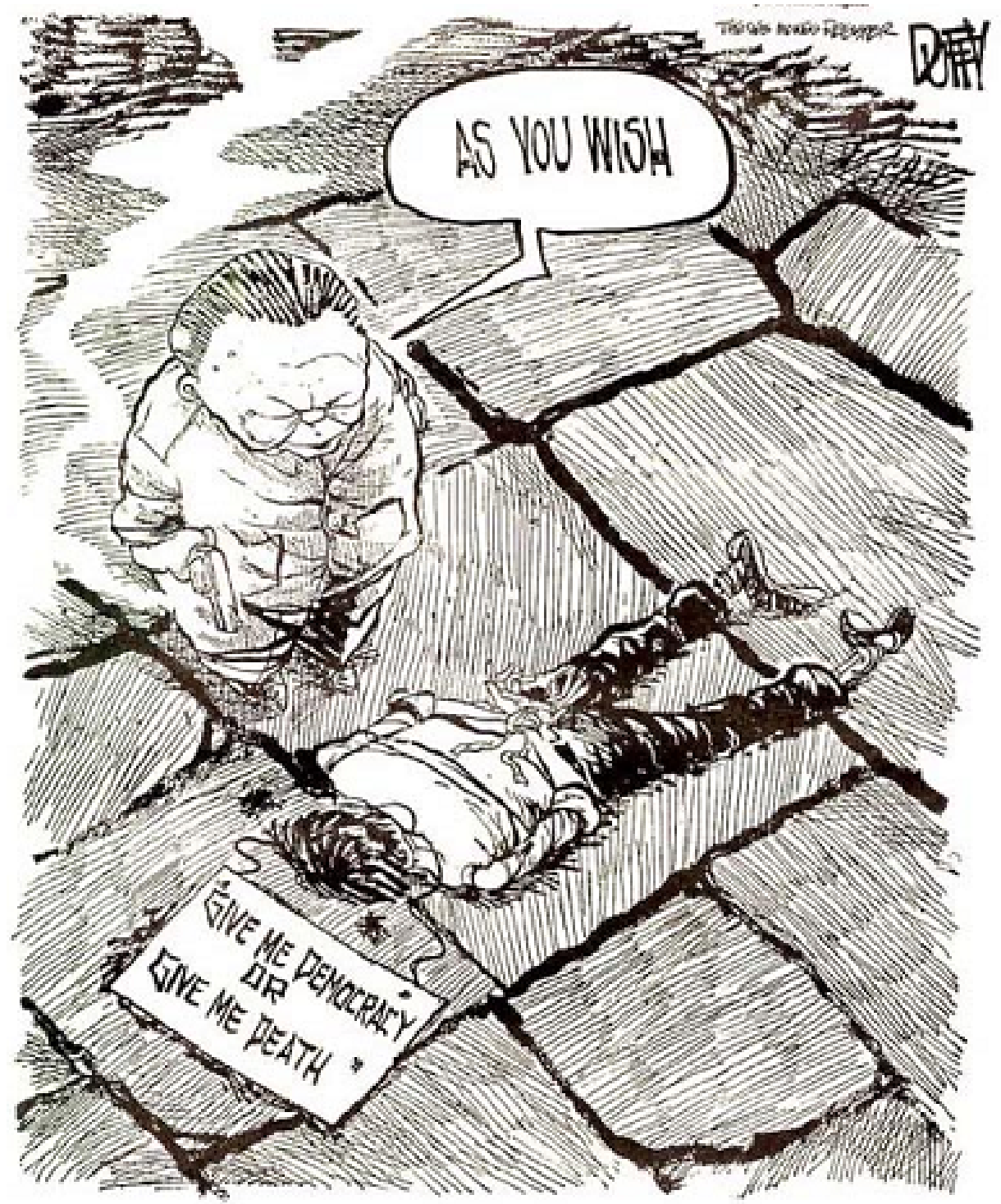

This cartoon (Duffy, 1990) requires the user to be able to identify the man with the gun in order to make sense of the image. The sentiment seen in the sign could be attributed to any number of movements in any number of places at any number of times and, therefore, cannot stand alone as a connection to a particular event. The background is likewise of little help in 
linking this cartoon to a particular event. It is only when we find that the gunman is Deng Xiaoping coupled either with the knowledge that he was the leader during the Tien’anmen Square Massacre or that the cartoon was published within days of that massacre that we can begin to understand what the cartoon is speaking to, and what it is saying. Here we find that a visual description might help identify the subject in that we could not fail to mention Deng in the description, providing the linchpin needed to derive the subject.
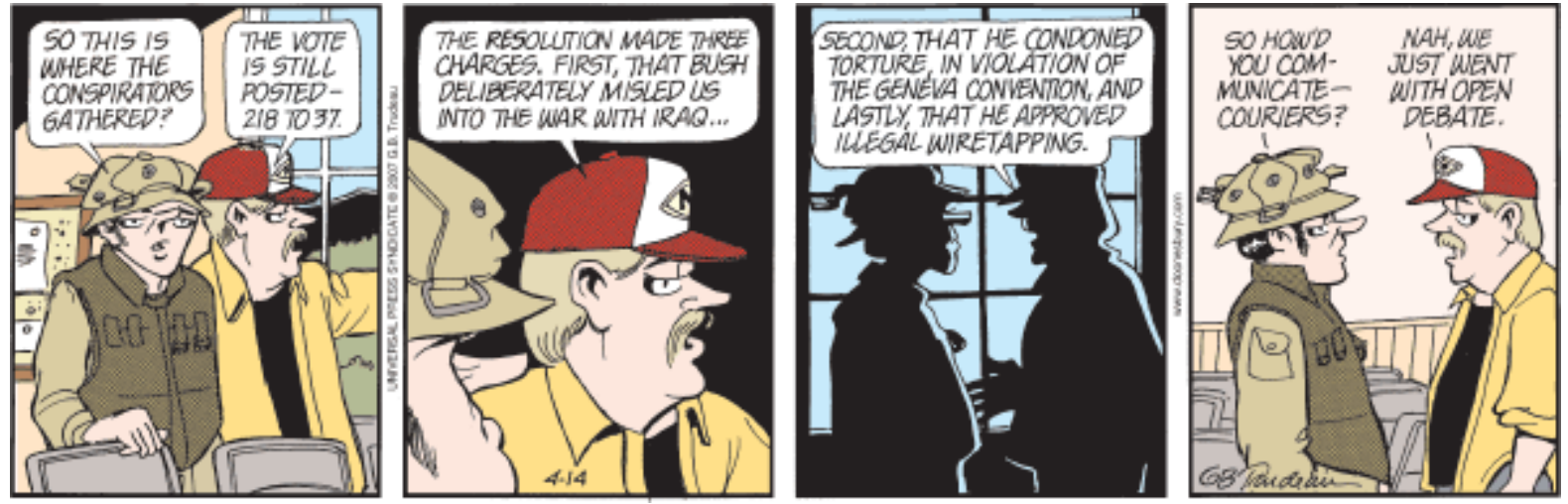

Political comic strips pose a different set of problems, some in common with cartoons and other unique to this type of commentary. Strips share with cartoons the need for the user to have at least a passing familiarity with the political events they examine and the need for basic cognitive skills and cultural knowledge. Differences sometimes include the need for familiarity with the characters and a need to see several strips in a series. Both are illustrated here (Trudeau, 2007), the former in the need to know that the man in the brown vest is a well-meaning but clueless reporter, the latter in the need to have seen preceding strips to know that this vote spoken of in this strip is a Massachusetts town's vote to impeach the junior President Bush. Neither of these would be necessary in a political cartoon, but are essential to determining the precise subject of a comic strip.

In addition to those difficulties, strips also present problems in description, mainly stemming from the verbal representation of action, which is much more abundant in a strip than 
in a single-panel cartoon. Any description of this strip would need to include the movement through the meeting hall, an action purely visual in the strip. And determining the level of specificity strips can be a problem as well: would it be enough to describe a character as angry, $\mathrm{r}$ must the gestures used to make this determination also be included?

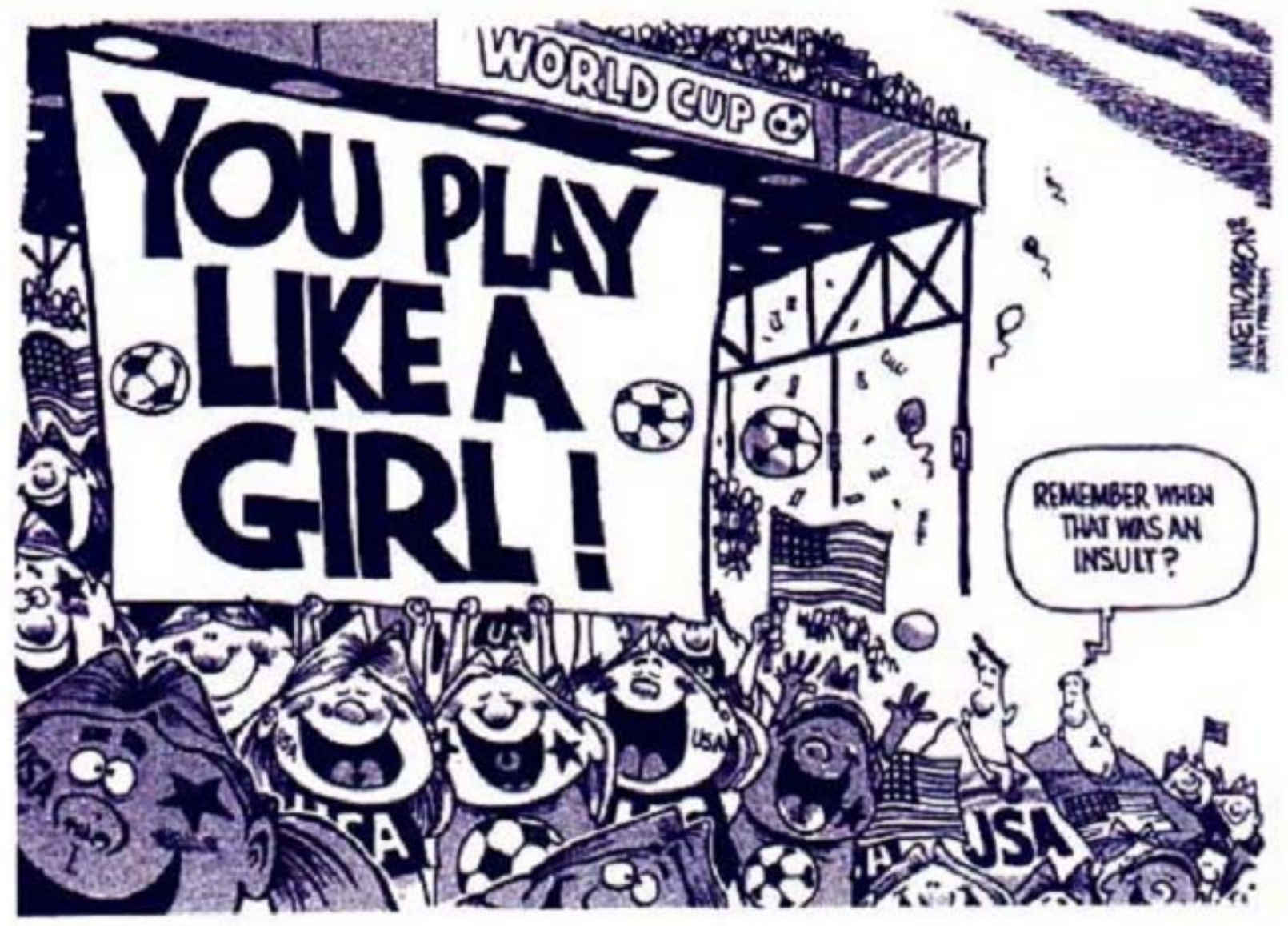

How is the subject of a cartoon properly described when there are two subjects? In this image (Thompson, 1999), we can rightly say that the subject is the euphoria of the Women's World Cup being played in the United States for the first time and the subsequent triumph of our team. Certainly, all the young girls in the cartoon, all the soccer balls and flags and balloons, point to this cartoon being a most approving commentary both on the American’s victory and on the World Cup as a month-long event being held in America or the first time. But this cartoon is also a commentary on the changing times, on Title IX, and on the rise of women's athletics in 
general. In addition to being about the event, it is also about the watershed moment of women's athletics finally arriving on the national stage and in the national media.

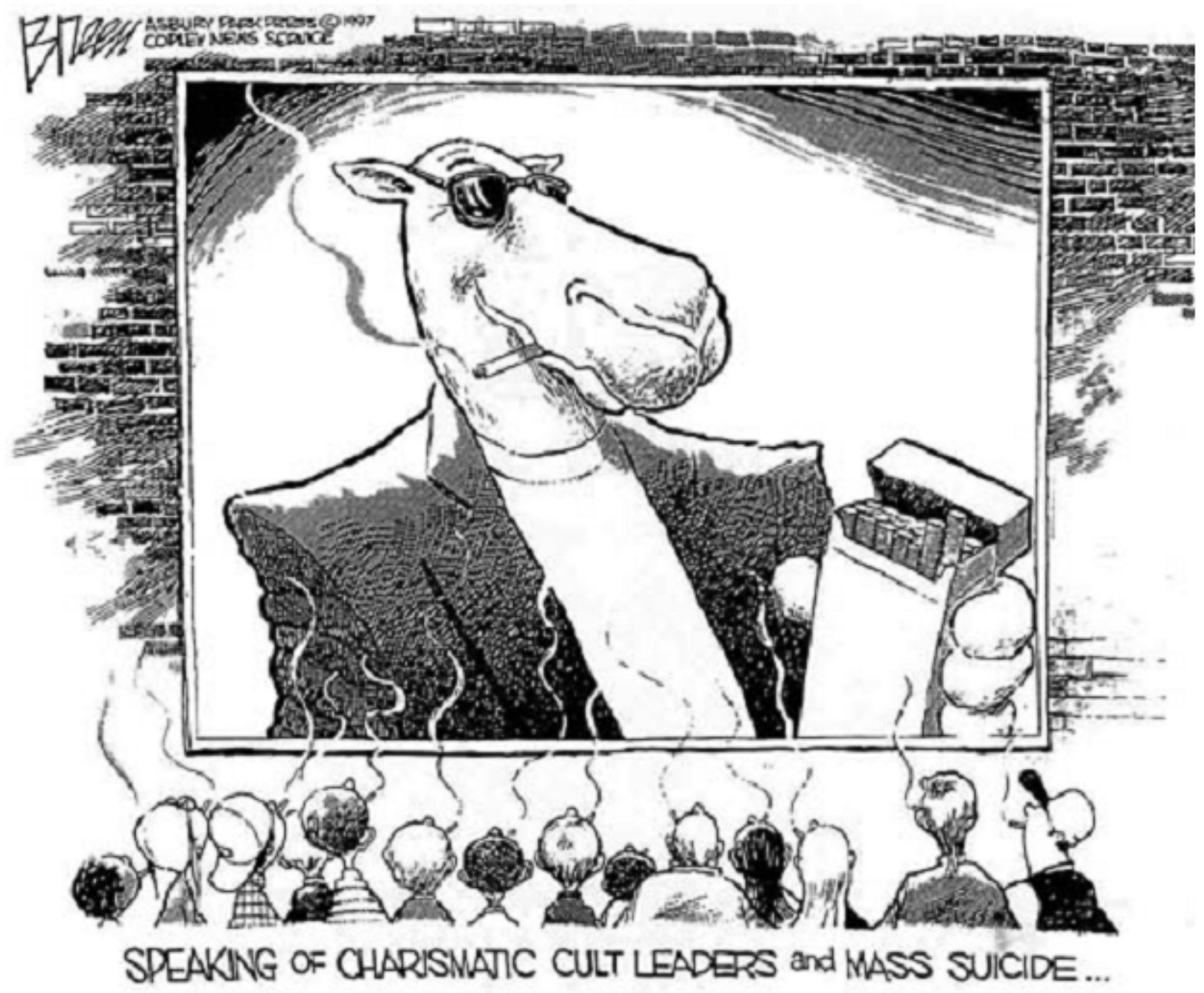

This cartoon (Breen, 1998) also has more than one subject, the difference being that while the previous example was self-contained (aside from a specific timeframe), this one refers to something neither named nor shown. The reference to smoking-related health problems in America’s youth is plain, along with the opinion that advertising for cigarettes that is directed at children is wrong. The un-named event that is not evident in the text or the drawing involves Marshall Applewhite, leader of the Heaven’s Gate cult that committed mass suicide with the arrival of the Hale-Bopp comet. The only way to make this connection is to know the date of the 
cartoon’s publication and that both Heaven’s Gate and cigarette advertising aimed at children were both news items at that time.

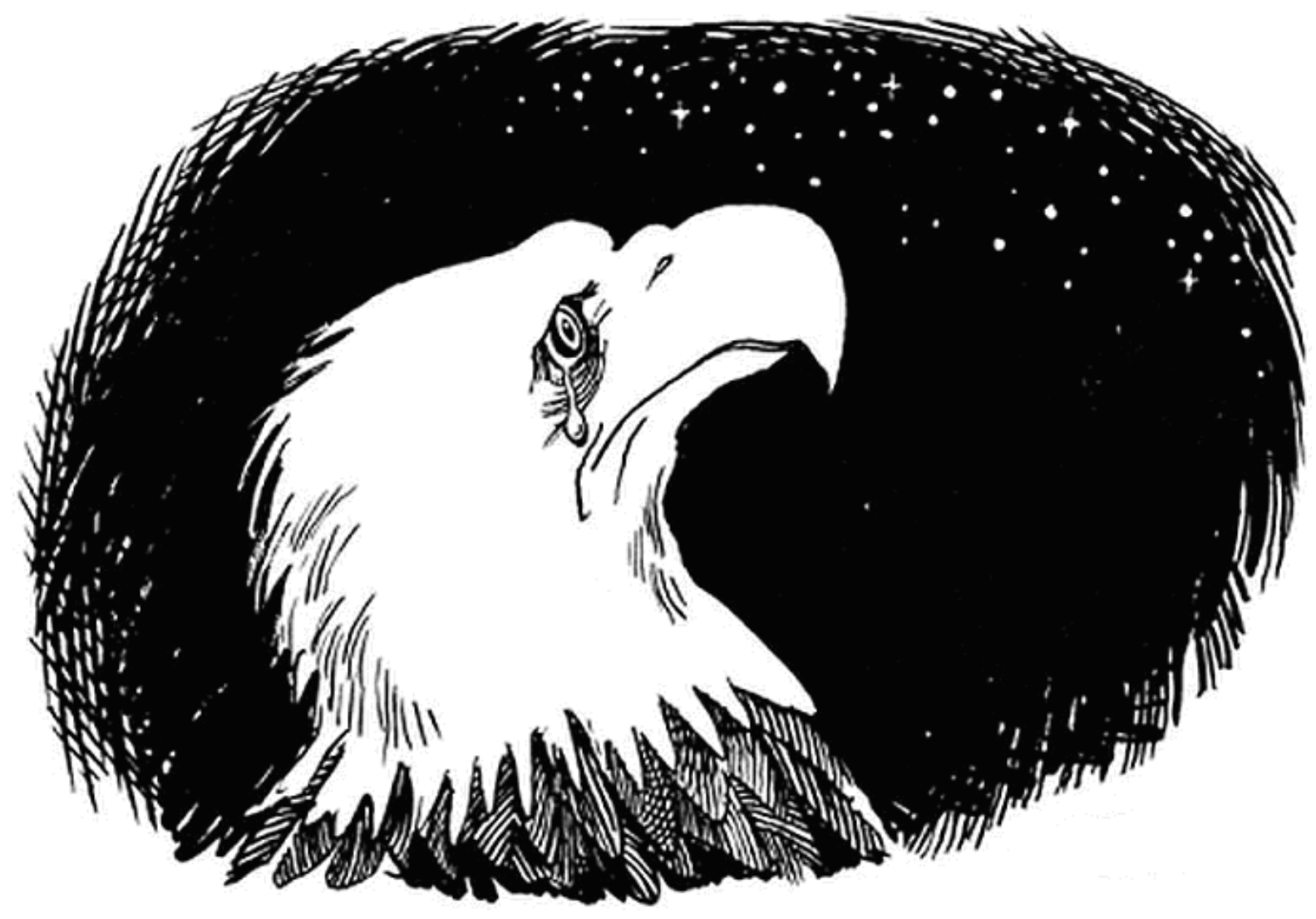

I submit that, with all of the bibliographic information removed, this cartoon (Marlette, 1991) cannot be subject cataloged or indexed by the image alone. While one might correctly guess the event that inspired it, one would never be certain. We might guess that the eagle represents America, that the tear represents some tragedy. At a stretch, we might guess that it is a space tragedy, but there is no way to know which one. If the date (1986) is included, it becomes easier to see that this is about the Challenger disaster, but absent this critical piece of information in addition to the aforementioned guesses, how can anyone correctly identify the subject of this cartoon? Here, visual description would not be as much a supplement to the subject as in other cartoons, as there is so little to describe. 


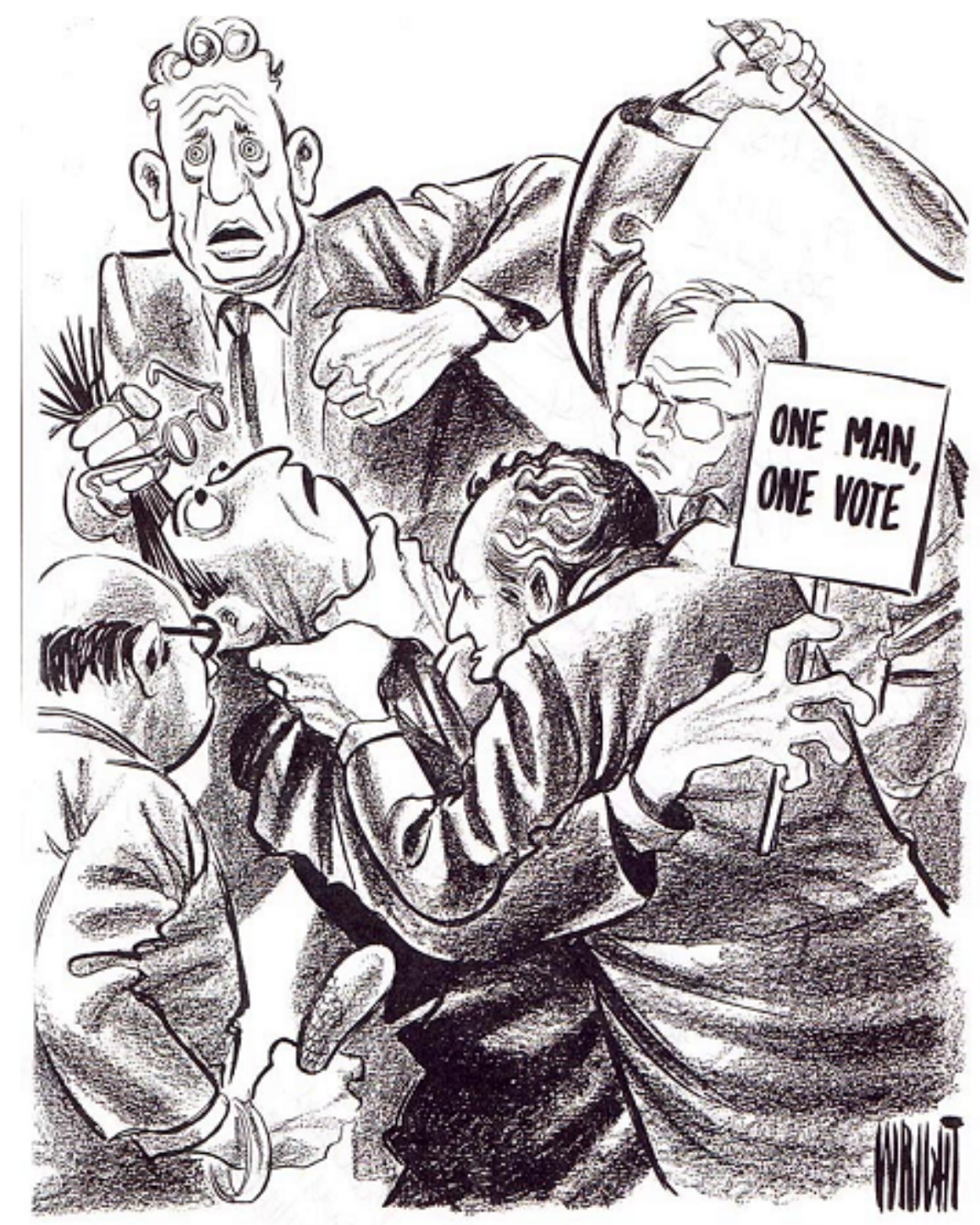

"We Must Be Selective About Those Who Eleet Us"

What was simulated previously is true here. This image (Wright, n.d.) represents the sum total of everything I know about this political cartoon. It is part of the Claude Pepper Collection, which is housed at Florida State University. It was found in a folder containing cartoons that dated from the 1940’s to the 1980’s. There was no newspaper name, although it was certainly from a newspaper. No date of any kind at all. The reverse of this clipping was an article about a local event, but did not contain enough information to make an assessment about the cartoon in any way. My best guess is that is has something to do with the reapportionment fights of the 
1950's, but it is only a guess. An intriguing piece of history is thus lost for want of a date, an identification of the people in the cartoon, or a note in the margin.

\section{Refining schema for indexing political cartoons}

As previously mentioned, the best schema for describing political cartoons is the VRA Core 4.0, but is should be modified to fit the specific needs of the genre. The VRA Core can handle what might loosely called "bibliographic data" as well as most other formal schema. Generally falling under the generic term “administrative data”, the bibliographic needs of political cartoons are fairly straightforward, as they have a number of similarities with other documents: authors or artist or some notation of the creator of the piece, date of publication (possibly the most crucial piece of information that can be included in the record), media used,

and the like. The one item that falls into this category that may not always be easily agreed on is the publisher. Fifty years ago, this would have been simple, but now we have fewer papers, and fewer still cartoonists working for them. Today, an artist may publish his or her work to a website, or distribute the work through a syndicate. Who, then, is the publisher? The artist? The website? The syndicate? While this is a problem to be dealt with, it is a small one when compared to those found in describing the cartoon itself and in naming the subject or subjects of that cartoon. Other administrative data, such as rights, retrieval, and physical description (size, medium, etc.) data, are also handled well by the VRA Core, and can be used for the description of political cartoons with little or no adaptation of the existing data dictionary.

\section{Inscription}

There are three major revisions to the VRA Core 4.0 that would need to be implemented in order for political cartoons to be properly described. First, the VRA Core already has an 
element designed to index the written word in images, called INSCRIPTION. This describes that author of the word if this is different from the creator of the work, the position of the text within the work, and what the text says. While of good use for, say, Renaissance art, it does not speak to the variety of text that can be connected with a political cartoon.

In cartoons, there can be four different kinds of text: the caption, which usually appears outside the scene shown in the cartoon; the spoken word, offered by one or more of the actors in the cartoon; the label, which explicitly identifies an object or person as a symbol; and background text, which is anything else. The INSCRIPTION element should be amended to be a superordinate element that includes these for types of text as subelements.

\section{Description}

The VRA Core includes an element called DESCRIPTION, which allows for a free-text account for the scene shown in the work. While this may be fruitful in small collections, large collections would quickly find that free-text description of anything leads to an inability to bring like items together: what one might call a group of "terrorists” another might call a group of “freedom fighters”; what this person calls "pristine” that person may call "undeveloped”; and so forth, with bias introduced at every turn, dividing similar cartoons from one another through individual and unstructured descriptions. To combat this, a scaled-down version of the CIDOC CRM should be used.

The CIDOC Conceptual Reference Model (2006), which is meant to bridge the gaps created between cultures by differing languages and by differing interpretations of events to form a universally applicable and interpretable ontology for the description of cultural objects. It codifies the recording of the relationships between the various parts of a painting, sculpture, or other cultural object to textually describe the object in question, although it does not impose any 
particular vocabulary for doing so. 84 classes of varying levels and 141 relationships between those classes comprise the CIDOC CRM. While it does not prescribe what the values for a given metadata element might be, it does prescribe how to show a relationship between elements and which elements might be valuable.

While the ideas behind the CRM are a good fit for what is being sought in our notional metadata schema, there are some problems with it. The number of classes and relationships make the CRM unwieldy in the hands of an amateur (and, it can be said, professionals). Given the short shelf-life of a cartoon and the subsequent need for quick indexing, along with the merits of harvesting folksonomic data, a reduction in possible terms should be made, eliminating the most specific terms in favor of fewer but more broadly applicable terms; instead of separating Movement, Modification, Birth, and Death from one another as different occurrences, we can use the less-specific Event to record these. With this in mind, we can reduce the 84 native CRM classes to perhaps eight (Gill, 2004). Couple this with a data dictionary that give strict instructions to record Panofsky's pre-iconographic data first - to describe the scene as factually as possible - and leaving the identification of the actors and objects in the cartoon to a separate activity would create a method of the structured description of the image shown in a cartoon.

\section{Subject}

The third necessary modification to the VRA Core is in the SUBJECT element. This also a free-text descriptor, but one that could easily use any of several authority files to record uniform data about events. This arrangement would only work for those works whose subjects are covered by the authority fields, which are updated periodically but tend to comment on events long past; while such files would comment of the Olympics in general, they would not comment on the Beijing Olympics is specific because it is to recent. Any authority file used to 
populate the SUBJECT field in the VRA Core would not be able to list headings in real time, quickly enough to keep up with the shelf-life of a cartoon. If we speculate that the subject of a political cartoon is the event which inspired the cartoon, then one possible solution - and one that must be thoroughly researched before implementation - is to use the headlines for the news stories as SUBJECT descriptor for cartoons. Even better would be to negotiate permission to record a persistent link from the record to the news story itself, allowing users who might find a cartoon potentially relevant to read about the event in question. Headlines are already produced quickly enough to keep up with events as they happen, and will be available for indexers to use as subject descriptors before the event fades into the background, making the description o the cartoon's subject that much more difficult and less likely to be done at all.

\section{$\underline{\text { References }}$}

Bedient, D. \& Moore, D. (1982). Student interpretations of political cartoons. Journal of Visual/Verbal Languaging, 5, 29-36.

Breen, S. (1998). [political cartoon]. From Best Editorial Cartoons of the Year: 1998, C. Brooks (Ed.) Gretna, Louisiana: Pelican Publishing Company.

Brinkman, D. (1968). Do editorial cartoons and editorials change opinions? Journalism Quarterly, 45, 724-726.

Carl, L. (1968). Political cartoons fail to reach readers. Journalism Quarterly, 45, 33-535. Chapple-Sokol, A. (1996). Indexing editorial cartoons. Special Libraries, 87(1), 21-31.

DeSousa, M. \& Medhurst, M. (1982). The editorial cartoon as visual rhetoric: Rethinking Boss Tweed. Journal of Visual/Verbal Languaging, 2, 43-52.

Duffy, B. (1990). [political cartoon]. From Best Editorial Cartoons of the Year, C. Brooks (Ed.). Gretna, Louisiana: Pelican Publishing Company.

Enser, P. (2000). Visual Information retrieval: Seeking the alliance of content-based and concept-based paradigms. Journal of Information Science, 26(4), 199-210. 
Hjørland, B. (2001). Towards a theory of aboutness, subject, topicality, theme, domain, field, content... and relevance. Journal of the American Society for Information Science and Technology, 52(9), 774-778.

Hunter, J., Moore, D., \& Sewell, E. (1991). The effects of teaching strategy and cognitive style on student interpretations of political cartoons. Journal of visual literacy, 11, 35-55.

Jörgensen, C. (2003a). Organizing and providing access to images. In Image retrieval: Theory and research (pp. 69-138). Lanham, MD: Scarecrow Press.

Kallaugher, K. (2007). [political cartoon]. Posted April 2, 2007. Retrieved from http://www.gocomics.com/kevinkallaugher/2007/04/02/ on September 19, 2008.

Landbeck, C. (2002). The organization and categorization of political cartoons: An exploratory study. Retrieved October 24, 3005, from Florida State University, Florida State University Libraries Web site: http://fs.aleph.fcla.edu/F/6MGECVXVDLJPVP5GATTHYN2 K4C44F1TMBG6X3KQ135LELP3A6F-04134?func=item-global\&doc_library=FSU01\&doc_ number $=002023409 \&$ year $=\&$ volume $=\&$ sub_library $=$ FSUER

Mai, J. (2004). Classification in context: Relativity, reality, and representation. Knowledge Organization, 31(1), 39-48.

Mai, J. (2005). Analysis in indexing: Document and domain centered approaches. Information Processing and Management, 41, 599-611.

Marlette, D. (1991). In your face: A cartoonist at work. New York: Houghton Mifflin. Maron, M. E. (1977). On Indexing, Retrieval and the Meaning of About. Journal of the American Society for Information Science, 28(1): 38-43.

Roberts, H. (2001). A Picture is worth a thousand words: Art indexing in electronic databases. Journal of the American Society for Information Science and Technology, 52(11), 911-916.

Shatford Layne, S. (1994). Some issues in image indexing. Journal of the American Society of Information Science and Technology, 45(8), 583-588.

Svenonius, E. (1994). Access to nonbook materials: The limits of subject indexing for visual and aural languages. Journal of the American Society for Information Science, 45(8), 600-606.

Swanson, D. (1986). Subjective versus objective relevance in bibliographic retrieval systems. Library Quarterly, 56(4), 389-398.

Thompson, M. (1999). [political cartoon]. From Best Editorial Cartoons of the Year: 2000, C. Brooks (Ed.) Gretna, Louisiana: Pelican Publishing Company. 
Trever, J. (2007). [political cartoon]. Posted April 6, 2007. Retrieved from http://www.abqjournal.com/cgi-bin/displayphoto_live.pl?table_name=trever_2007\&ID=22456 on September 19, 2008.

Trudeau, G. (2007). [comic strip]. Posted April 14, 2007. Retrieved from http://www.gocomics.com/doonesbury/2007/04/14 on September 19, 2008.

Weitenkampf, F. (1946). Political cartoons as historical documents. Bulletin of the New York Public Library, 50(3), 171-176.

Wright. (n. d.). Unknown publisher. From the Claude Pepper Library, Florida State University. 